Document downloaded from:

http://hdl.handle.net/10251/157584

This paper must be cited as:

Broatch, A.; Martín, J.; García Martínez, A.; Blanco-Cavero, D.; Warey, A.; Domenech, V. (2019). Application of a zero-dimensional model to assess the effect of swirl on indicated efficiency. International Journal of Engine Research. 20(8-9):837-848.

https://doi.org/10.1177/1468087418779726

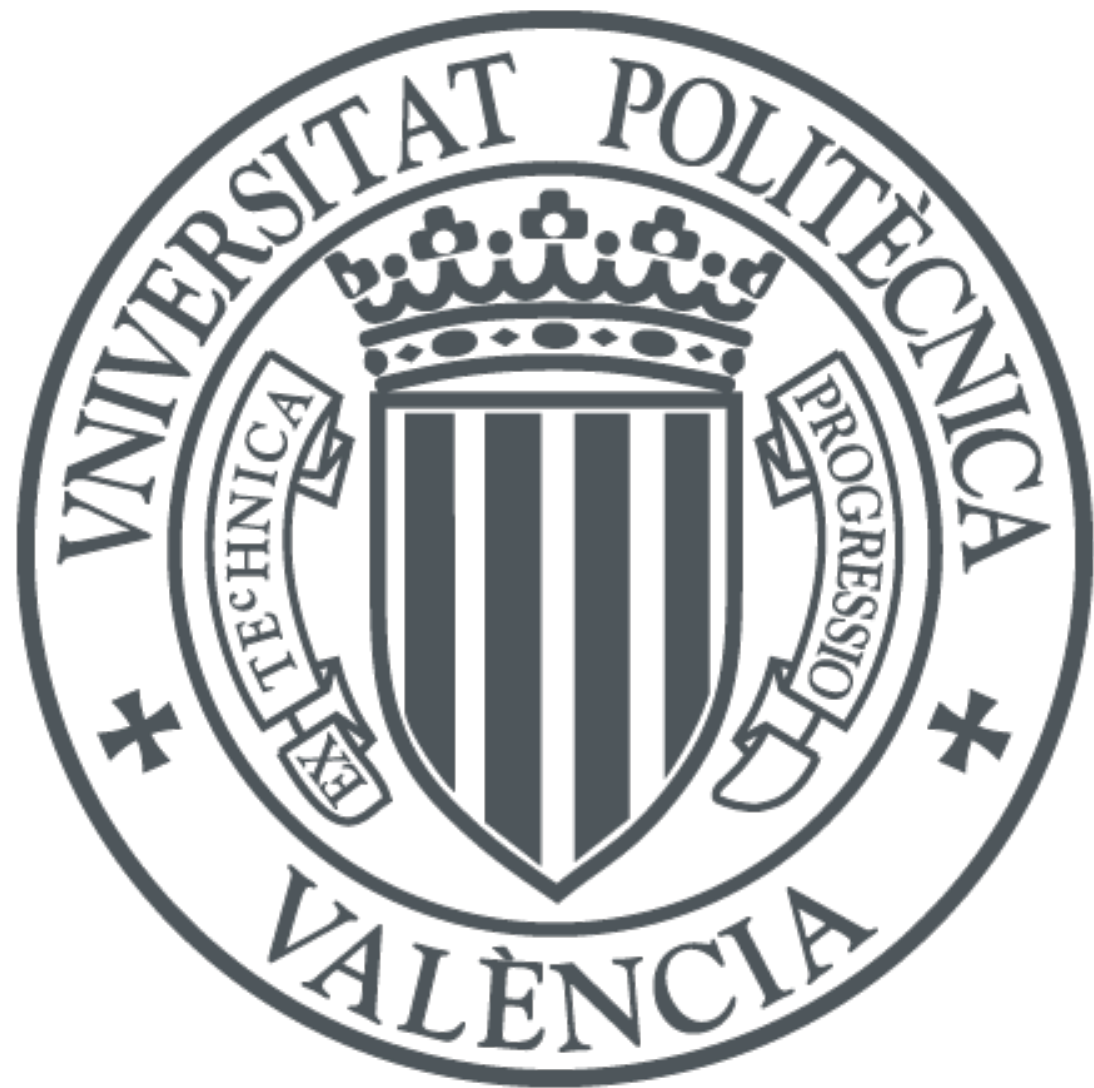

The final publication is available at

https://doi.org/10.1177/1468087418779726

Copyright SAGE Publications

Additional Information

This is the author s version of a work that was accepted for publication in International Journal of Engine Research. Changes resulting from the publishing process, such as peer review, editing, corrections, structural formatting, and other quality control mechanisms may not be reflected in this document. Changes may have been made to this work since it was submitted for publication. A definitive version was subsequently published as https://doi.org/10.1177/1468087418779726 


\title{
Application of a OD model to assess the effect of swirl on indicated efficiency
}

\author{
Alberto Broatch ${ }^{1}$, Jaime Martín', Antonio García1, Diego Blanco-Cavero', Alok Warey² and \\ Vicent Domenech ${ }^{2}$
}

\begin{abstract}
Increasing ICE efficiency continues being one of the main goals of engine research. To achieve this objective, different engine strategies have been developed. However, the assessment of these techniques is not straightforward due to their influence on various intermediate phenomena inherent to the combustion process, which finally result on indicated efficiency trade-offs. During the present work, a new methodology to assess these intermediate imperfections on gross indicated efficiency (GIE) using a OD model is developed. This methodology is applied to a swirl parametric study, where it has been concluded that the heat transfer and the rate of heat release are the single relevant changing phenomena. Results show that HT always increases with swirl affecting negatively GIE (around $-0.5 \%$ ), while the impact of combustion velocity is not monotonous. It is enhanced up to a certain SR (it changes with engine speed) at low engine speed (resulting in a increment of $+1.7 \%$ in GIE) but it is slowed down at high engine speed with the consequent worsening of GIE (-0.8\%).
\end{abstract}

\section{Keywords}

Internal combustion engine, Combustion analysis, Efficiency, Heat Transfer, Split of Losses,swirl

$\begin{array}{ll}\text { Abbreviations } \\ \text { CA50 } & \begin{array}{l}\text { Crank Angle in which } 50 \% \text { of the fuel mass is } \\ \text { burned }\end{array} \\ \text { EGR } & \text { Exhaust Gas Recirculation } \\ \text { GIE } & \text { Gross Indicated Efficiency } \\ \text { HCCI } & \text { Homogeneous Charge Compression Ignition } \\ \text { HSDI } & \text { High Speed Direct Injection } \\ \text { HT } & \text { Heat Transfer } \\ \text { ICE } & \text { Internal Combustion Engine } \\ \text { IVC } & \text { Intake Valve Closing } \\ \text { OEM } & \text { Original Equipment Manufacturer } \\ \text { PCCI } & \text { Premixed Charge Compression Ignition } \\ \text { RoHR } & \text { Rate of Heat Release } \\ \text { SOE } & \text { Start of Energizing Time } \\ \text { SR } & \text { Swirl Ratio } \\ \text { TDC } & \text { Top Dead Center }\end{array}$

\section{Introduction}

Despite the efforts made by OEMs to optimize the ICE operation, there is still much to do in terms of performance optimization. In the last years, the efforts have been mainly focused on the reduction of $N O_{X}$ and soot emissions by means of different injection strategies [1], high pressure fuel injection systems [2], multiple injections [3], high boost pressure [4], exhaust gases recirculation (EGR) $[5,6]$, variable valve timing $[7,8]$, high swirl $[9,10,11]$ and tumble ratios [12, 13] and new clean fuels [14, 15]. However, the impossibility to overcome the regulation only managing internal processes, has led to the generalization of aftertreatment systems [16], giving room to the other main engine issue: engine fuel consumption. Hence, there is an increasing interest towards the optimization of fuel consumption, and the reduction of $\mathrm{CO}_{2}$ emissions [17] by means of different technologies. To comply with the upcoming requirements, new combustion concepts such as HCCI [18] and PCCI [19], new automotive engine concepts

\footnotetext{
${ }^{1}$ CMT-Motores Térmicos, Universitat Politcnica de Valncia, Camino de Vera s/n, 46022, Valencia, Spain

${ }^{2} \mathrm{GM}$ Global Research and Development, Pontiac, USA

\section{Corresponding author:}

Jaime Martín, CMT-Motores Térmicos, Universitat Politcnica de Valncia, Camino de Vera s/n, 46022, Valencia, Spain

Email: jaimardi@mot.upv.es
} 
such as downsizing [20, 21] and two-stroke engines [22] and new control strategies [23] are being studied.

A first step to tackle the fuel consumption improvement topic is to identify the direction in which the research has to be addressed and to quantify its possible gain. A regular approach to analyze the impact of a certain strategy is to perform parametric studies of a variable to assess its effect on the gross indicated efficiency (GIE). However, usually there are several intermediate processes affected by this change which can finally affect in contrary ways to gross indicated efficiency, thus providing a final resultant effect. With the regular approach, these intermediate phenomena are ignored and the engine is considered almost as a black box with some outputs depending directly on some inputs.

The analysis of the intermediate processes affected when a certain strategy is followed is interesting because it helps to identify the controlling factors which finally affect efficiency. Two of the main intermediate phenomena affected by the use of these strategies are heat transfer (HT) and combustion development. Furthermore, these intermediate factors can have competing effects on engine efficiency and it is not always easy to quantify and isolate them. Additionally, this split of effects can not be performed directly from the measured in-cylinder pressure, which is the result of all the phenomena involved.

A way to asses the impact of these intermediate changes on GIE could be the comparison between the real thermodynamic cycle at each parametric level and the maximum efficiency theoretical cycle (Otto). Differences between an ideal and a real cycle are due to the addition of intermediate "imperfections" such as heat transfer, real working gas, combustion velocity and phasing, incomplete combustion, blow-by losses and non centered valve timing. If these imperfections are estimated at each parametric level, its impact on GIE due to the studied variable change could be assessed. This methodology is called in some works [24] "Split of losses".

Unfortunately, these changes are inherent to the studied strategy and it is not possible to isolate them in a real engine. Therefore, simulation tools are necessary in order to quantify independently the impact of these interconnected effects. Unlike 3D models, OD thermodynamic models do not require high computational effort and they are able to give accurate results in short time [16] given a suitable preliminary calibration. Thus, a predictive OD model [25] is used in this work to solve the mass and energy conservation equations during closed cycle so that the instantaneous state of the gas within the combustion chamber (pressure and temperature) is obtained.

In the case of Diesel engines, a common strategy followed nowadays to enhance GIE is the use of high Swirl Ratios (SR). Air motion in the chamber is a key issue to improve the air-fuel mixing process to achieve faster burning rates [16], therefore modern Diesel engines are designed to generate swirl in the chamber that leads to enhanced turbulence during the combustion development, thus affecting emissions and consumption. On the one hand, swirl increases HT which has a negative impact on efficiency but, on the other hand, it also enhances the mixing process resulting in a faster combustion. If the impact of HT on engine efficiency is assessed separately from the combustion process, it is easier, for instance, to evaluate the potential benefit obtained through the use of thermal isolation when high SR is promoted.

In this scenario, the objective of this work is twofold:

1. On the one hand, to develop and describe a methodology capable of assessing and quantifying the impact of the in-cylinder processes inherent to the combustion development on the engine efficiency.

2. On the other hand, to apply this methodology to evaluate the relevant phenomena affecting GIE in a swirl parametric study.

\section{Experimental and theoretical tools}

\section{Engine characteristics}

The study was carried out in a HSDI Diesel engine equipped with a Common-Rail fuel injection system, whose main characteristics are presented in Table 1 . In spite of the more difficult control and possible cylinder dispersion in comparison with a single cylinder engine, a 4 cylinder engine was selected to replicate the thermal response, key issue in the work, of the production engine under different engine operating conditions. Modifications were done to some systems of the original engine to attain better control of the engine fluids, thus, the EGR and oil coolant circuits were separated from the engine coolant circuit. Therefore, heat rejection to oil, coolant, intercooler and EGR heat exchangers could be analyzed independently. Besides, the original air-air intercooler was replaced by an air-water heat exchanger. To obtain experimental information for the 
lumped conductance model commissioning and validation, 88 thermocouples were installed at different locations of the engine block and cylinder-head [26].

As commented, swirl ratio, defined as the ratio between air angular speed at the IVC and the crankshaft angular speed, can be varied in this engine by means of a valve located upstream of the helical port of each cylinder. When this valve is completely open, the air comes into the cylinder through both the tangential and helical ports leading to the lowest swirl ratio $(\mathrm{SR}=1.4)$. The more closed the valve gets, the lower the air mass flow through the helical port is, leading to a higher mass flow through the swirl generator port (tangential) and the consequent higher swirl ratio. The highest swirl level $(\mathrm{SR}=3)$ is reached when the valve is completely closed.

The engine control was performed by using a commercial controller system (DRIVVEN). This tool works as a conventional control unit and, additionally, it is able to acquire, analyze and record different instantaneous signals from the engine (e.g., in-cylinder pressure, intake and exhaust pressures, rail pressure and the current clamp signal corresponding to the injection command) as well as real-time control of different combustion variables such as combustion phasing. DRIVVEN also was used to control the engine settings by modifying the required parameters such as the EGR valve position, VGT position, injection quantity and timing and common-rail, swirl and throttle valves.

\section{Test cell characteristics}

The engine was installed in a fully instrumented test cell, which scheme is shown in Figure 1. The characteristics of the most relevant instrumentation are presented in Table 2. The installation was instrumented to acquire the standard measurements necessary to perform the complete combustion diagnosis and model the internal energy terms with an in-house developed tool called CALMEC [27, 28]; and the data required for the experimental external thermal balances [29]. In-cylinder pressure was measured with 4 Kistler 6125C piezo-electric transducers flush mounted in the glow plug hole of each cylinder. The signal provided by each sensor was conditioned with a Kistler 5011B amplifier, collected by DRIVVEN and then filtered following the methodology explained in [30].

Additionally, detailed heat fluxes to coolant, oil, intercooler and EGR cooler were obtained by means of specific instrumentation to measure fluid flows and temperatures. Furthermore, intake and exhaust conditions were measured in order to perform a detailed analysis of the in-cylinder conditions during both close and open cycle: air and fuel mass flows, gas temperatures and pressures at different intake and exhaust positions were recorded at low frequency $(10 \mathrm{~Hz})$ and then averaged. Liquids temperatures are measured with thermoresistances, which are more accurate than the thermocouples used to measure cylinder-head and cylinder liner temperatures.

\section{OD models}

For the present study two different OD single-zone thermodynamic models (CALMEC and siCiclo) were used. Both of them share the same main hypothesis:

- Chamber pressure and temperature are assumed to be spatially uniform.

- Three species (air, fuel vapor and stoichiometric combustion products) are considered [25].

- Ideal gas law is used to calculate gas mean temperature.

- A filling and emptying model is used to calculate the trapped mass [31].

- Specific heat of the gas depends on both temperature and composition [32].

- Chamber is assumed to be an open system during closed cycle to consider fuel injection and instantaneous blow-by leakage calculated with a model based on the isentropic nozzle flow [31].

- Chamber volume deformation is calculated by means of a simple deformation model [33].

- Heat transfer to the chamber walls is calculated with a modified Woschni-like model [34].

An in-house methodology [28] was applied to determine some experimental uncertainties related to in-cylinder pressure (pressure pegging and TDC position) along with some engine characteristics (dynamic and static compression ratios and HT convective model adjustment). Besides, a lumped conductance model was used to calculate wall temperatures in the chamber and ports along with the heat rejection repartition to coolant and oil. It consists of 102 nodes in the cylinder head, 66 in the liner, 10 in the piston and some boundary nodes that take into account the oil, coolant, fresh air, in-cylinder gas, and intake and exhaust gases. A detailed description of this model can be seen at [35]. 
On the one hand, CALMEC is the combustion analysis tool that allows calculating the RoHR from the instantaneous evolution of in-cylinder gas properties by solving the $1^{\text {st }}$ law of thermodynamics and modeling the internal energy terms based on the instantaneous pressure evolution. The model considers all the relevant engine subsystems through the combination of both physical and semi-empirical submodels to calculate the heat transfer flow to combustion chamber walls and ports, split of mechanical losses and intake and exhaust processes [27].

On the other hand, siCiclo is a predictive tool that, using the RoHR as main input, is able to calculate the in-cylinder pressure evolution with the purpose of predicting engine performance and fuel consumption or obtaining boundary conditions for specific combustion models with higher computational requirements [36, 37]. This model performs the simulation of the same phenomena described in the previous paragraph but in this case the main input is the RoHR instead of the in-cylinder pressure. In some applications, such as emissions prediction, or when the combustion details must be accounted for [38, 39, 40], it is imperative to consider more than one zone to obtain acceptable results. However, once calibrated and validated, the OD single-zone model used is suitable for the accurate calculation of the pressure evolution with the purpose of predicting indicated parameters and engine performance. Starting from Intake Valve Closing (IVC) conditions ( $\mathrm{p}, \mathrm{m}$ and $\mathrm{T}$ ) the OD single-zone model is able to calculate the gas state up to the Exhaust Valve Opening (EVO), thus being a predictive tool that allows rapid parametric explorations of different engine operating conditions and geometric configurations.

\section{Methodology}

The objective of this work is to develop a methodology capable of assessing and quantifying separately the impact of the in-cylinder processes inherent to the combustion development and heat transfer on the engine efficiency and its application to a specific study of SR. The study was structured in 5 main parts:

1. As engine losses are a key focus in this study, an initial calibration of the HT and mechanical losses model was performed. This was done by using data from both motoring and combustion tests (detailed in [28]).

2. Experimental measurement of SR an injection settings parametric studies was performed in the installation described in the experimental tools section in different operating conditions.

3. Combustion diagnosis was performed to obtain the experimental RoHR of each parametric level.

4. Proposal of the split of losses methodology with some specific simplifications.

5. Finally, the methodology is applied to asses separately the relevant phenomena affecting the GIE, as shown in the Results section.

\section{HT model adjustment}

An initial adjustment was carried out to ensure the accurate estimation of the heat transfer to different engine parts, where special attention was paid to the heat rejection in the combustion chamber. Thus, tests in motored conditions were used to adjust some uncertainties (real compression ratio, TDC position and the constant of the deformation model) along with the constants of the Woschni-like equation velocity term, $C_{W 1}$ and $C_{W 2}$ (see appendix). The adjustment method is based on the application of the first law of thermodynamics to obtain the RoHR residuals (it should be zero because no fuel is injected). A multi-variable linear regression is used to find the values of the parameters by means of the least square method. More details of the process can be found in [28].

Geometry of the lumped conductance model [41] nodes was adjusted to fit the real engine geometry and to facilitate the comparison between experimental and modeled nodes temperatures. Once the lumped model was built and included in the 0-D models, the experimental temperatures obtained with the thermocouples were used to validate the results provided by the lumped conductance model, obtaining a mean error about $5 \mathrm{C}$ and a maximum error lower than $10 \mathrm{C}$ in most cases [26].

\section{Test methodology of parametric studies}

The swirl parametric study was performed at six different operating points (k-points). These k-points, whose significant variables are reflected in Table 3 , were chosen for being the most representative of an emission homologation cycle. In the present work these k-points will be named by using a composition of 2 numbers, the first one means the engine speed in revolutions per minute while the second one refers to the BMEP in bar (engine speed_BMEP). 
SR was variated from 1.4 to 3 in 4 levels $(1.4 / 2 / 2.5 / 3)$ at 6 k-points (see Table 3). These ratios were provided by the engine manufacturer as function of the swirl valve position. Hence, the complete test matrix is composed of 6 (k-points) x 4 (swirl levels) and three repetitions of each point were measured and then averaged.

To isolate the effects of the studied variables, all engine parameters (except the analysed one) were kept constant. Therefore, the parametric sweep was performed with the same intake temperature (45C) and trapped mass at the IVC, as well as the same combustion phasing (CA50=13 ATDC) and injected fuel mass, which was fixed for each k-point. The intake pressure was adjusted at each swirl level to get the same inlet mass flow (see Experimental and theoretical tools section). Furthermore, coolant (87C) and oil (95C) temperatures were kept constant in all the tests, thus avoiding interferences in the heat fluxes and friction losses when the experimental sweeps were performed.

With respect to the injection strategy, it consisted of two pilot injections to reduce the combustion noise and a main injection event. Pilot quantities $(1.5 \mathrm{mg} / \mathrm{cc})$ and dwell times (0.8 ms) were kept constant for all the points. On the other hand, the main injection quantity was varied to meet the required BMEP at each k-point (even though it changed when the parametric variation was performed because the fuel mass was maintained) and the timing of this injection was set to obtain a CA50 of 13 in each test. Hence, the complete injection train was moved with swirl changes.

To ensure a stable thermal behavior of the engine, stabilization periods of about 30 minutes were required. It was assumed that thermal stabilization was reached when the temperature variation rate of all the liquids (coolant, cooling water and oil) was lower than $1 \mathrm{C} / \mathrm{min}$. The thermal stabilization was evaluated in the liquids instead of the material for two reasons. On one hand, liquids reached their thermal stabilization later than engine material due to the higher thermal inertia and the high thermal diffusivity of the metal. Thus, when the liquid stabilization was reached, metal temperature was also stable. Gas temperatures (intake air and exhaust gases) were also controlled, but their stabilization was faster than in the case of liquids, thanks to the lower thermal inertia and the higher convective HT between those fluids and the measurement devices (thermocouples and thermoresistances).

\section{Combustion analysis}

The starting point for the analysis is performing the combustion diagnosis in all the points included in the experimental matrix. The in-house developed combustion diagnosis tool (Calmec) allows obtaining the results derived from the experimental data, such as GIE, pumping work, brake thermal efficiency (BTE) and the heat transfer in the combustion chamber, key issues for the study.

\section{Split of losses analysis}

It is well-known that the maximum theoretical efficiency reachable by an internal combustion engine is the Otto cycle, which maximum efficiency is the same for every operating point since it only depends on the compression ratio. Starting from the Otto cycle, the real cycle of a specific point can be obtained by means of the subtraction of all the cycle imperfections to this maximum efficiency or "ceiling". The total effect of the imperfections is different at each point, resulting on distinct real GIE.

The cycle imperfections affecting a real cycle are the following:

1. Heat transfer: this effect takes into account the energy lost due to heat rejection to the combustion chamber walls.

2. Real working gas: in a real ICE the working gas is composed by air, fuel and burnt gases unlike the onlyair gas computed in the Otto cycle. Furthermore, the thermodynamic properties of the mixture also change as temperature and composition change during the cycle evolution, therefore they are not constant as in the Otto cycle.

3. RoHR phasing: that accounts for the non-optimized combustion centering.

4. RoHR velocity: since real combustions are not instantaneous, there is an efficiency reduction due to this effect.

5. Incomplete combustion: in the ideal cycle the total amount of fuel is burnt but this is not the case in a real engine.

6. Blow-by: it accounts for the enthalpy loss due to the gas leakage from the chamber to the crankcase. The ideal cycle does not take into account this phenomenon.

7. Non centered valve timing: OEMs usually advance the EVO to reduce the pumping work, thus increasing the 
BTE. However, since the focus of this study is the GIE, any reduction of the expansion stroke reduces it.

The evaluation of each imperfection separately is an interesting way to assess which are the causes of the efficiency change in a parametric study. Moreover, if some variables are controlled during the experimental measurement, the analysis can be simplified while keeping its potential outcomes. Thus, if the parametric study is performed maintaining the same IVC conditions (pressure, mass, temperature and composition), computing the effect of the real working gas is not necessary because it would be the same within the parametric study. Another possible experimental way to simplify this analysis is to perform the parametric study under the same combustion centering (CA50), thus eliminating the combustion phasing effect.

Finally, taking into account that the incomplete combustion and blow-by terms are small (the change in any of them in the parametric study is lower than $0.1 \%$ in all cases) and the non centered valve timing is roughly the same at a given operating point, it can be assumed that evaluating their possible change in a parametric study is not necessary.

If the methodology explained is followed when performing the experimental measurement and the minor terms are neglected, it is possible to simplify the analysis from 7 to 2 steps, hence heat transfer and RoHR velocity would be responsible for the change of indicated efficiency, thus simplifying the comparison among parametric levels.

Taking into account the previous comments, the next steps will be followed to perform the split of losses:

1. Original cycle: simulation of k-points in SiCiclo using experimental conditions ( $p, T$, composition at IVC) and imposing the experimental RoHR. GIE deviation lower than $0.3 \%$ was achieved in all the cases.

2. Then, the adiabatic cycle at each parametric level was calculated with SiCiclo, thus obtaining the efficiency achievable in adiabatic conditions.

3. The difference between the original and adiabatic efficiencies (steps 1 and 2) is the impact of HT on GIE. Then, $\Delta \mathrm{HT}$ effect at each level is computed as the difference of the modeled GIE between a certain parametric level and the reference one. This term computes the impact of HT change on GIE promoted by the variation of the studied parameter.
4. The adiabatic cycles calculated in step 2 should reach the same GIE in all parametric levels if the combustion velocity was the same. Therefore, if this adiabatic efficiency is not the same it is due to the changes in the combustion velocity promoted by the variation of the studied parameter. The difference between a level and the reference one will be called $\Delta$ RoHR velocity effect.

Once the methodology has been simplified up to this point, it will be applied to a swirl parametric study in which the simplifications above described can be assumed, as presented in the next section.

\section{Results and discussion}

Following the methodology explained in the previous section, the experimental matrix measurement was performed maintaining constant IVC conditions (pressure, mass, temperature and composition) and combustion centering. Since changes in no-burnt term, blow-by and non-centered valves timing are negligible, only 2 of the 7 possible imperfections will be evaluated. Taking into account these considerations, the methodology was applied to a swirl parametric study.

For the sake of brevity, and taking into account that the studied k-points can be grouped according to their behavior, only three of them $\left(1500 \_8,1500 \_14\right.$ and 3000_14) will be analyzed in detail. Since 1500_8, 2000_2 and 2000_5 points have a similar behavior, it was decided to show 1500_8 (intermediate load). It was found another set of high load tests with similar trends which consists of 2000_14 and 3000_14, from which the last k-point was chosen. The last studied k-point was 1500_14 that shows an intermediate behavior between the 2 previous groups. In this way, the study shows a load sweep at constant speed (1500 rpm) and an engine speed sweep at constant load (14 bar).

Figure 2 shows the experimental GIE at different SR levels and k-points. The top plot shows the absolute values while in the bottom plot it can be seen the variation of this term respect to the lowest SR, which will be the reference for each operating point. In the 1500_8 k-point, GIE increased almost linearly up to $1.2 \%$ at $\mathrm{SR}=2.5$. However, at $\mathrm{SR}=3$ it drops until reach a level $-0.4 \%$ below the reference SR. When the 1500_14 k-point is analyzed, a similar behavior with a maximum at $\mathrm{SR}=2.5$ is found, where a global positive effect of $0.8 \%$ on GIE was reached. Similarly to the previous 
k-point, a decrease of GIE at the highest SR is observed, although in this case it is smoother, thus still having a positive effect with respect to $\mathrm{SR}=1.4(+0.3 \%)$. In the case of 3000_14, there is not such maximum and a continuous drop up to $\mathrm{SR}=2.5(-0.2 \%)$ is observed. Then, a deeper decrease was produced worsening the GIE $-1.2 \%$ with respect to the lowest $\mathrm{SR}$.

With these results in mind, it is evident that SR has a positive effect on the GIE at low engine speed until reaching a determined value, while it is not interesting at high engine speed. However, in order to analyze deeply the observed behavior, the described methodology is going to be applied. As starting point, Figure 3 shows the RoHR and HT evolution in 1500_14. It can be seen that increasing SR enhances air-fuel mixing during the first stages of the main injection-combustion event due to the higher air velocity which implies higher turbulent behavior. This mixing process improvement leads to an enhancement of the combustion that can be seen in the sharper slope of the main RoHR until the peak. Then, a deterioration of the RoHR peak with $\mathrm{SR}$ is observed, especially at $\mathrm{SR}=2.95$. This combustion velocity limitation contributes to worsen the RoHR evolution just after the peak, thus extending the last part of the combustion. The combination of these changes observed in the RoHR results on different GIE variations depending on the SR level and the operation point. Unlike RoHR, HT increases monotonically with SR due to the higher air velocity and the consequent enhanced heat transfer coefficient.

The evolution through the methodology steps will be extensively graphed at 1500_14 and the final result will be presented in a graph. After that, the final results of the other two k-points will be shown. Starting from the original efficiency at this k-point (purple bars in Figure 4), the first step is to compute the adiabatic cycle at each parametric level. The gain achieved at each level is plotted in red bars in Figure 5. Longer bars mean more HT, which is directly transferred into an efficiency loss, thus their difference respect to the lowest level are computed with negative sign in Figure 5 as well. These variations are the effect of the HT change due to the swirl variation on indicated efficiency ( $\Delta \mathrm{HT}$ effect). As observed, the increased HT due to the higher gas velocity is responsible for a reduction of $-0.4 \%$ in GIE at the highest SR.

Once the HT effect has been analyzed, it is easy to asses the combustion velocity change impact on indicated efficiency. Since there are no additional effects, the absolute adiabatic efficiency achieved at each SR (purple bars + red bars in Figure 4) should be the same if combustion was the same at every level. Since it is not the case, this difference is only attributable to the combustion velocity change. When comparing all the absolute levels with the lowest one, the effect of combustion change due to the swirl variation on indicated efficiency ( $\triangle \mathrm{RoHR}$ velocity effect) is obtained and also plotted in Figure 4. As can be seen, this effect increases GIE at intermediate swirl levels $(+0.8 \%$ at $\mathrm{SR}=2.5$ ) but this increment reduces at the highest $\mathrm{SR}$ $(+0.3 \%)$. This non-monotonous behavior is due to the RoHR changes (Figure 3) promoted by SR explained in previous paragraphs. As commented, SR affected positively in the first stages of the combustion, but negatively afterwards. The balance between these opposite variations, positive and with a rising trend up to $\mathrm{SR}=2.5$, starts to decay beyond this swirl level.

Both $\Delta \mathrm{HT}$ and $\Delta \mathrm{RoHR}$ effects are replotted together in Figure 6 along with the experimental measured GIE variation at 1500_14. It can be seen that the experimental change is explained by the addition of both effects. As shown, the experimental GIE variation follows the same trend than the $\Delta$ RoHR velocity effect but its level is slightly lower because the $\Delta \mathrm{HT}$ effect decreases monotonously. Therefore, it can be concluded that at this point the dominant effect when SR is swept is the variation of the combustion velocity rather than the HT increment.

The second point of the study is 1500_8, which presents a similar behavior than 1500_14. If the ROHR evolution at this point is observed in Figure 7, the enhancement of the main slope and peak with swirl up to $S R=2.5$ can also be discerned as in the previous point. Additionally, at this operating conditions there is also an improvement of the combustion after the maximum RoHR when SR is incremented, leading to shorter combustion durations. Regarding the HT evolution, there is no change respect to the other point and the heat rejection to the chamber continuously rises with SR. Again, the methodology is applied to this point obtaining Figure 8. The analysis at $1500 \_8$ is similar to that performed at 1500_14 but, in this case, both the increase due to the $\Delta$ RoHR velocity effect up to $\mathrm{SR}=2.5(+1.7 \%)$ and the decrease beyond this level $(+0.1 \%)$ are steeper. The $\Delta \mathrm{HT}$ effect is almost the same than at higher load $(-0.5 \%$ at $\mathrm{SR}=3)$, resulting in a slightly lower variation of the experimental GIE variation but with 
the same trend than the $\Delta$ RoHR velocity effect.

The last point of the study is 3000_14, whose combustion and HT evolution are plotted in Figure 9. The behavior of the combustion with SR is similar to that found at 1500_14 but with a deeper decay of the peak and the stages after it, leading to a dramatic enlargement of the combustion duration. The HT evolution follows the same pattern than at the other k-points. Finally, the methodology is applied to this point in Figure 10. There, it can be seen that the $\Delta$ RoHR velocity effect presents a maximum at $\mathrm{SR}=2(+0.1 \%)$ but it does not even compensate the drop promoted by the $\Delta \mathrm{HT}$ effect. After $\mathrm{SR}=2$, both effects are negative causing an even worst GIE variation $(-1.2 \%$ at $\mathrm{SR}=3)$.

According to the results obtained it can be summarized that regarding the effect of SR on the heat transfer, it is similar in all the analyzed conditions, with a monotonous effect on GIE about $0.5 \%$ at the highest SR level. However, the effect of SR on the combustion process is not the same: in global terms increasing slightly SR enhances the combustion, being the effect on GIE higher at low engine speed and load. In all cases the combustion changes lead to a GIE penalty at very high SR levels.

\section{Conclusions}

During the present work, a new methodology to assess the changes inherent to the combustion process on GIE when performing a parametric study has been developed. This methodology consists on comparing the real cycle of every level within a parametric sweep with the maximum efficiency thermodynamic theoretical cycle. Differences in GIE between an ideal and a real cycle are due to the addition of the impact of intermediate changes or "imperfections" such as heat transfer, real working gas, combustion velocity and phasing, incomplete combustion, blow-by losses and non centered valves timing. Additionally, if a certain experimental methodology is followed, these 7 imperfections reduces up to only 2: heat transfer and combustion velocity. Since these changes are inherent to the studied strategy and it is not possible to isolate and assess them separately in a real engine, a OD predictive model was used. Once these imperfections are computed at each parametric level, its impact on GIE due to the studied variable change was assessed.
Finally, this methodology has been applied to a swirl parametric study at three different operating points. At 1500_8, the combination of heat transfer and RoHR effects ( $\Delta \mathrm{HT}$ and $\triangle \mathrm{RoHR}$ respectively) led to a maximum GIE at $\mathrm{SR}=2.5$, where the $\Delta \mathrm{RoHR}$ effect $(1.7 \%)$ is higher than the $\Delta \mathrm{HT}(-0.5 \%)$. Similar results are observed at 1500_14 with a maximum GIE also located at $\mathrm{SR}=2.5$, where $\Delta$ RoHR velocity effect and $\Delta \mathrm{HT}$ effect are $1.1 \%$ and $-0.3 \%$ respectively. Finally, no GIE improvement was achieved at 3000_14 when swirl is swept, where both $\triangle$ RoHR and $\Delta \mathrm{HT}$ tend to decrease $-0.8 \%$ and $-0.4 \%$ respectively. As a general trend, HT always increases with swirl affecting negatively GIE, while the impact of combustion velocity is not monotonous. This velocity is enhanced up to a certain SR at low engine speed but it is slowed down at high engine speed with the consequent impact on GIE.

\section{Acknowledgements}

This work was partially funded by GM Global R\&D and the Government of Spain through Project TRA2013-41348-R. In addition, the authors acknowledge that some equipment used in this work has been partially supported by FEDER project funds (FEDER-ICTS-2012-06), framed in the operational program of unique scientific and technical infrastructure of the Ministry of Science and Innovation of Spain. Diego Blanco-Cavero is partially supported through contract FPI-S2-2016-1356 Of the Programa de Apoyo para la Investigacin y Desarrollo (PAID) of Universitat Politcnica de Valncia. 


\section{References}

1. Mohan B, Yang W and Chou SK. Fuel injection strategies for performance improvement and emissions reduction in compression ignition engines-A review. Renewable and Sustainable Energy Reviews 2013; 28: 664-676. DOI:10.1016/j.rser.2013.08.051.

2. Agarwal AK, Srivastava DK, Dhar A et al. Effect of fuel injection timing and pressure on combustion, emissions and performance characteristics of a single cylinder diesel engine. Fuel 2013; 111: 374-383. DOI: 10.1016/j.fuel.2013.03.016.

3. Hiwase SD, Moorthy S, Prasad H et al. Multidimensional Modeling of Direct Injection Diesel Engine with Split Multiple Stage Fuel Injections. Procedia Engineering 2013; 51: 670-675. DOI:10.1016/j.proeng. 2013.01.095.

4. Canakci M. Combustion characteristics of a DI-HCCI gasoline engine running at different boost pressures. Fuel 2012; 96: 546-555. DOI:10.1016/j.fuel.2012.01. 042 .

5. Pan M, Shu G, Wei H et al. Effects of EGR, compression ratio and boost pressure on cyclic variation of PFI gasoline engine at WOT operation. Applied Thermal Engineering 2014; 64(1-2): 491-498. DOI:10.1016/j. applthermaleng.2013.11.013.

6. Fontana $\mathrm{G}$ and Galloni E. Experimental analysis of a spark-ignition engine using exhaust gas recycle at WOT operation. Applied Energy 2010; 87(7): 2187-2193. DOI:10.1016/j.apenergy.2009.11.022.

7. Verhelst S, Demuynck J, Sierens R et al. Impact of variable valve timing on power, emissions and backfire of a bi-fuel hydrogen/gasoline engine. International Journal of Hydrogen Energy 2010; 35(9): 4399-4408. DOI:10.1016/j.ijhydene.2010.02.022.

8. Fontana $\mathrm{G}$ and Galloni E. Variable valve timing for fuel economy improvement in a small spark-ignition engine. Applied Energy 2009; 86(1): 96-105. DOI: 10.1016/j.apenergy.2008.04.009.

9. Perini F, Miles PC and Reitz RD. A comprehensive modeling study of in-cylinder fluid flows in a high-swirl, light-duty optical diesel engine. Computers \& Fluids 2014; 105: 113-124. DOI:10.1016/j.compfluid.2014.09. 011 .
10. Wei S, Wang F, Leng X et al. Numerical analysis on the effect of swirl ratios on swirl chamber combustion system of DI diesel engines. Energy Conversion and Management 2013; 75: 184-190. DOI:10.1016/j. enconman.2013.05.044.

11. Olmeda P, Martín J, Blanco-Cavero D et al. Effect of in-cylinder swirl on engine efficiency and heat rejection in a light-duty diesel engine. International Journal of Engine Research 2017; 18(1-2): 81-92. DOI:10.1177/ 1468087417693078

12. Benajes J, Novella R, De Lima D et al. Analysis of the combustion process, pollutant emissions and efficiency of an innovative 2-stroke HSDI engine designed for automotive applications. Applied Thermal Engineering 2013; 58(1-2): 181-193. DOI:10.1016/j. applthermaleng.2013.03.050.

13. Olmeda P, Martín J, Novella R et al. An adapted heat transfer model for engines with tumble motion. Applied Energy 2015; 158: 190 - 202. DOI:10.1016/j.apenergy. 2015.08.051.

14. Sandalcı T and Karagöz Y. Experimental investigation of the combustion characteristics, emissions and performance of hydrogen port fuel injection in a diesel engine. International Journal of Hydrogen Energy 2014; : 1-10.DOI:10.1016/j.ijhydene.2014.09.044.

15. Sorate KA and Bhale PV. Biodiesel properties and automotive system compatibility issues. Renewable and Sustainable Energy Reviews 2015; 41: 777-798. DOI: 10.1016/j.rser.2014.08.079.

16. Heywood J. Internal Combustion Engines Fundamentals. New York: McGraw-Hill, 1988.

17. European Parliament. Regulation (EU) No 333/2014 of the European Parliament and of the Council of 11 March 2014 amending Regulation (EC) No 443/2009 to define the modalities for reaching the 2020 target to reduce $\mathrm{CO} 2$ emissions from new passenger cars. Official Journal of the European Union 2014; L103 Vol 57: 1521.

18. Ryan $\mathrm{T}$ and Callahan $\mathrm{T}$. Homogeneous Charge Compression Ignition of Diesel Fuel. SAE Technical paper 961160 1996; DOI:10.4271/961160.

19. Kiplimo R, Tomita E, Kawahara $\mathrm{N}$ et al. Effects of spray impingement, injection parameters, and EGR on the combustion and emission characteristics of a PCCI 
diesel engine. Applied Thermal Engineering 2012; 37 165-175. DOI:10.1016/j.applthermaleng.2011.11.011.

20. Köfer T, Lamping M, Kolbeck A et al. The potential of downsizing Diesel engines considering performance and emissions challenges. IMechE 2008; .

21. Thirouard M and Pacaud P. Increasing Power Density in HSDI Engines as an Approach for Engine Downsizing. SAE Int J Engines 2010; 3(2): 56-71. DOI:10.4271/ 2010-01-1472.

22. Tribotte P, Ravet F, Dugue V et al. Two Strokes Diesel Engine - Promising Solution to Reduce CO2 Emissions. Procedia - Social and Behavioral Sciences 2012; 48: 2295-2314. DOI:10.1016/j.sbspro.2012.06.1202.

23. Molina S, Guardiola C, Martín J et al. Development of a control-oriented model to optimise fuel consumption and NO X emissions in a DI Diesel engine. Applied Energy 2014; 119: 405-416. DOI:10.1016/j.apenergy. 2014.01.021.

24. Weberbauer F, Rauscher M, Kulzer A et al. Generally applicate split of losses for new combustion concepts. MTZ worldwide 2005; 66(2): 17-19. DOI:10.1007/ BF03227736.

25. Payri F, Olmeda P, Martín J et al. A complete OD thermodynamic predictive model for direct injection diesel engines. Applied Energy 2011; : 4632-4641DOI: 10.1016/j.apenergy.2011.06.005.

26. Broatch A, Olmeda P, García A et al. Impact of swirl on in-cylinder heat transfer in a light-duty diesel engine. Energy 2017; 119: 1010-1023. DOI:10.1016/j.energy. 2016.11.040.

27. Payri F, Olmeda P, Martín J et al. A New Tool to Perform Global Energy Balances in DI Diesel Engines. SAE Int J Engines 2014; DOI:10.4271/2014-01-0665.

28. Benajes J, Olmeda P, Martín J et al. A new methodology for uncertainties characterization in combustion diagnosis and thermodynamic modelling. Applied Thermal Engineering 2014; 71: 389-399. DOI:10.1016/j. applthermaleng.2014.07.010.

29. Payri F, Martín J, García A et al. Experimental and Theoretical Analysis of the Energy Balance in a DI Diesel Engine. SAE Technical paper 2015-01-1651 2015; DOI:10.4271/2015-01-1651.
30. Payri F, Olmeda P, Guardiola C et al. Adaptive determination of cut-off frequencies for fil ltering the incylinder pressure in diesel engines combustion analysis. Applied Thermal Engineering 2011; 31(14-15): 28692876. DOI:10.1016/j.applthermaleng.2011.05.012.

31. Payri F, Galindo J, Martín J et al. A Simple Model for Predicting the Trapped Mass in a DI Diesel Engine. SAE Technical Paper 2007-01-0494 2007; DOI:10.1016/ j.applthermaleng.2005.10.021.

32. Lapuerta M, Armas O and Hernández JJ. Diagnosis of DI Diesel combustion from in-cylinder pressure signal by estimation of mean thermodynamic properties of the gas. Applied Thermal Engineering 1999; c: 513-529. DOI:10.1016/S1359-4311(98)00075-1.

33. Payri F, Molina S, Martín J et al. Influence of measurement errors and estimated parameters on combustion diagnosis. Applied Thermal Engineering 2006; 26(2-3): 226-236. DOI:10.1016/j.applthermaleng.2005.05.006.

34. Payri F, Margot X, Gil A et al. Computational Study of Heat Transfer to the Walls of a DI Diesel Engine. SAE Technical paper 2005-01-0210 2005; DOI:10.4271/ 2005-01-0210.

35. Torregrosa AJ, Olmeda P, Martín J et al. A Tool for Predicting the Thermal Performance of a Diesel Engine. Heat Transfer Engineering 2011; 32(10): 891904. DOI:10.1080/01457632.2011.548639.

36. Benajes J, Novella R, De Lima D et al. Analysis of combustion concepts in a newly designed two-stroke high-speed direct injection compression ignition engine. International Journal of Engine Research 2015; 16(1, SI): 52-67. DOI: $\{10.1177 / 1468087414562867\}$.

37. Benajes J, Martín J, Novella R et al. Understanding the performance of the multiple injection gasoline partially premixed combustion concept implemented in a 2Stroke high speed direct injection compression ignition engine. Applied Energy 2016; 161: 465-475. DOI: $\{10.1016 /$ j.apenergy.2015.10.034\}.

38. Hiroyaus H, Kadota $\mathrm{T}$ and Arai M. Development and use of a spray combustion modelin to predict Diesel-engine efficiency and pollutant emissions. 1. Combustion modelling. Bulletin of the JSME-Japan Society of Mechanical Engineers 1983; 26(214): 569575. DOI:10.1299/jsme1958.26.569. 
39. Egnell R. Combustion Diagnostics by Means of Multizone Heat Release Analysis and NO Calculation. SAE 1998; DOI:10.4271/981424.

40. Rakopoulos CD, Rakopoulos DC, Giakoumis EG et al. Validation and sensitivity analysis of a two zone Diesel engine model for combustion and emissions prediction. Energy Conversion and Management 2004; 45(9-10): 1471-1495. DOI:10.1016/j.enconman.2003.09.012.

41. Torregrosa A, Olmeda P, Degraeuwe B et al. A concise wall temperature model for DI Diesel engines. Applied Thermal Engineering 2006; 26(11-12): 13201327. DOI:10.1016/j.applthermaleng.2005.10.021. 


\section{Figures}

Figure 1. Experimental set-up

Figure 2. Absolute value and variations of GIE in swirl sweep

Figure 3. RoHR and HT evolution at 1500_14

Figure 4. Experimental GIE, adiabatic effect and $\Delta$ RoHR effect at 1500_14

Figure 5. Adiabatic effect and $\Delta \mathrm{HT}$ effect at 1500_14

Figure 6. Split of losses study at 1500_14

Figure 7. RoHR and HT evolution at 1500_8

Figure 8. Split of losses study at 1500_8

Figure 9. RoHR and HT evolution at 3000_14

Figure 10. Split of losses study at 3000_14 


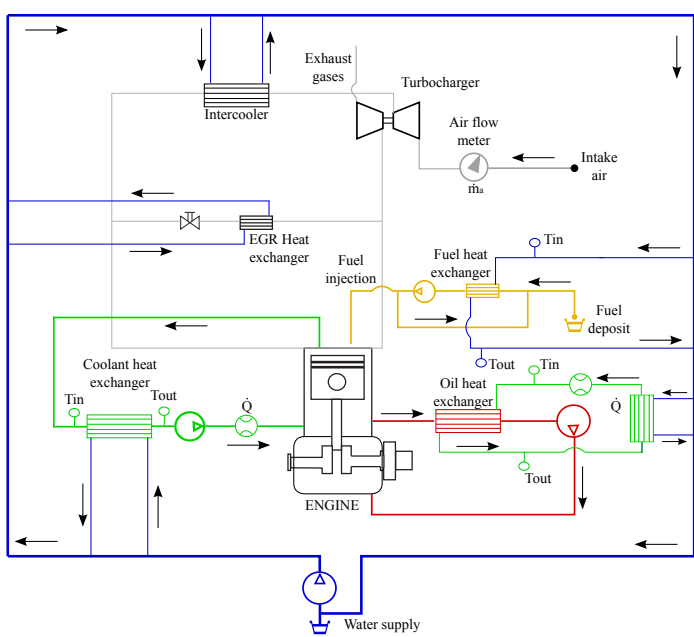

Figure 1. Experimental set-up

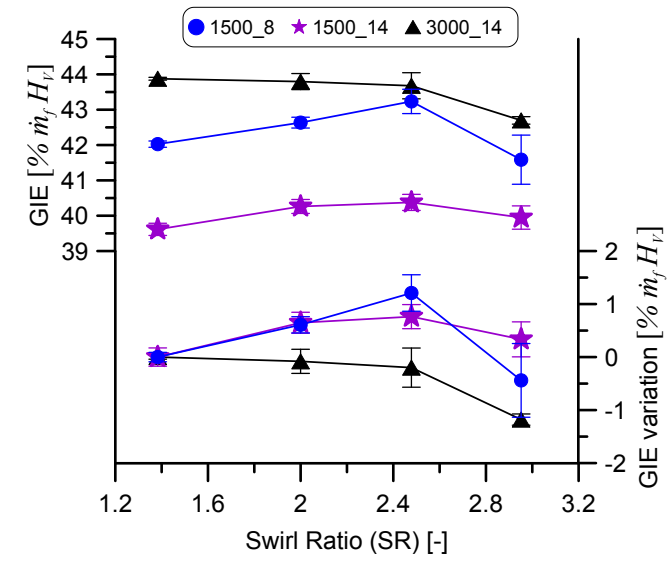

Figure 2. Absolute value and variations of GIE in swirl sweep

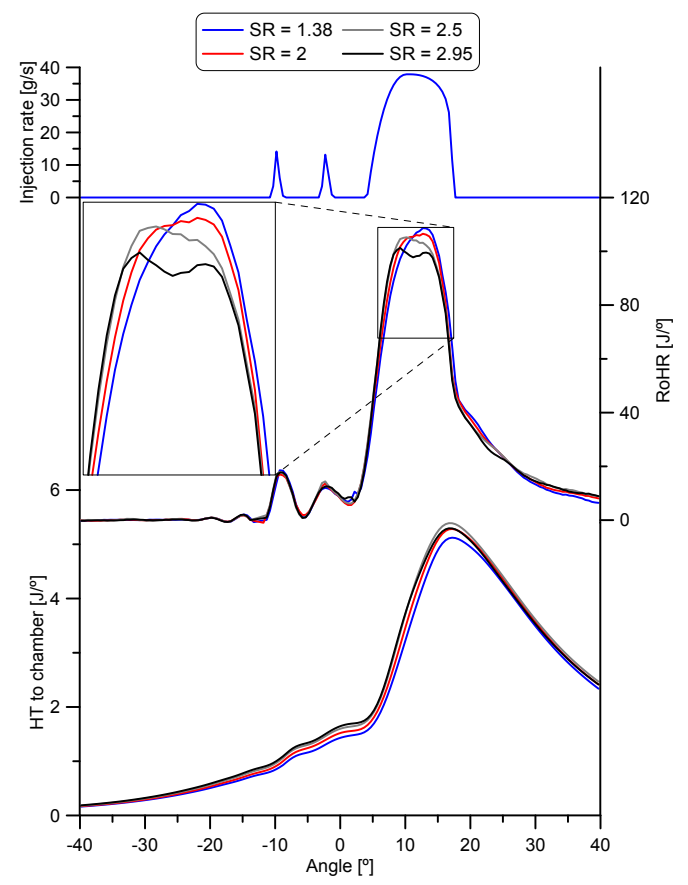

Figure 3. RoHR and HT evolution at 1500_14

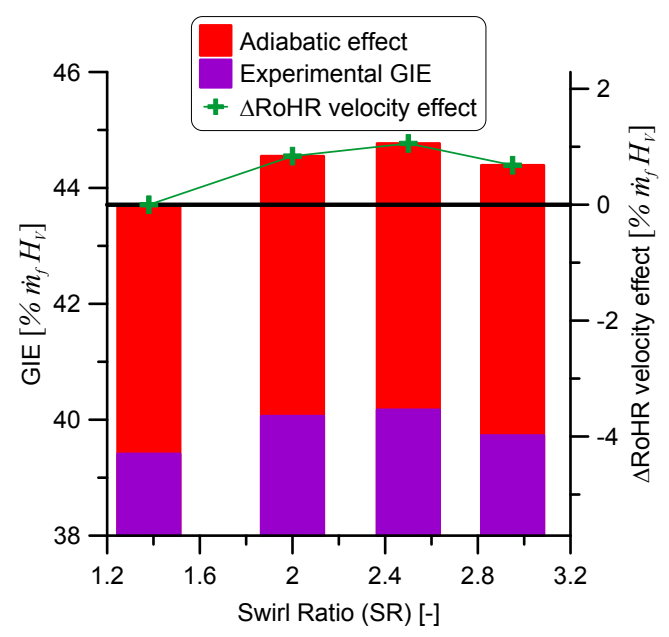

Figure 4. Experimental GIE, adiabatic effect and $\Delta \mathrm{RoHR}$ effect at 1500_14

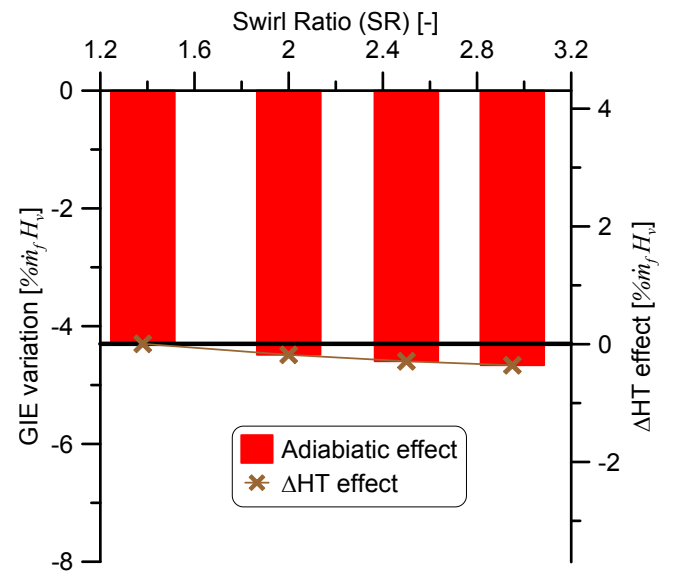

Figure 5. Adiabatic effect and $\Delta \mathrm{HT}$ effect at 1500_14

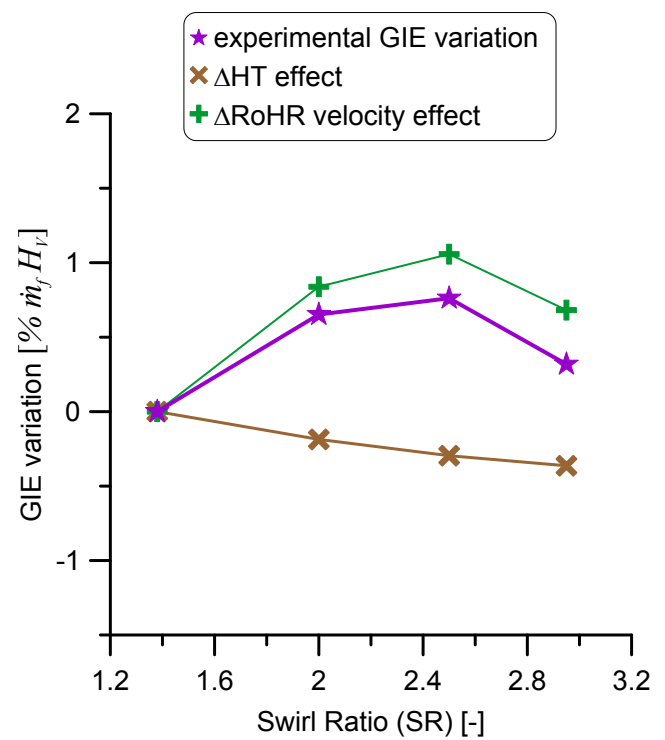

Figure 6. Split of losses study at 1500_14 


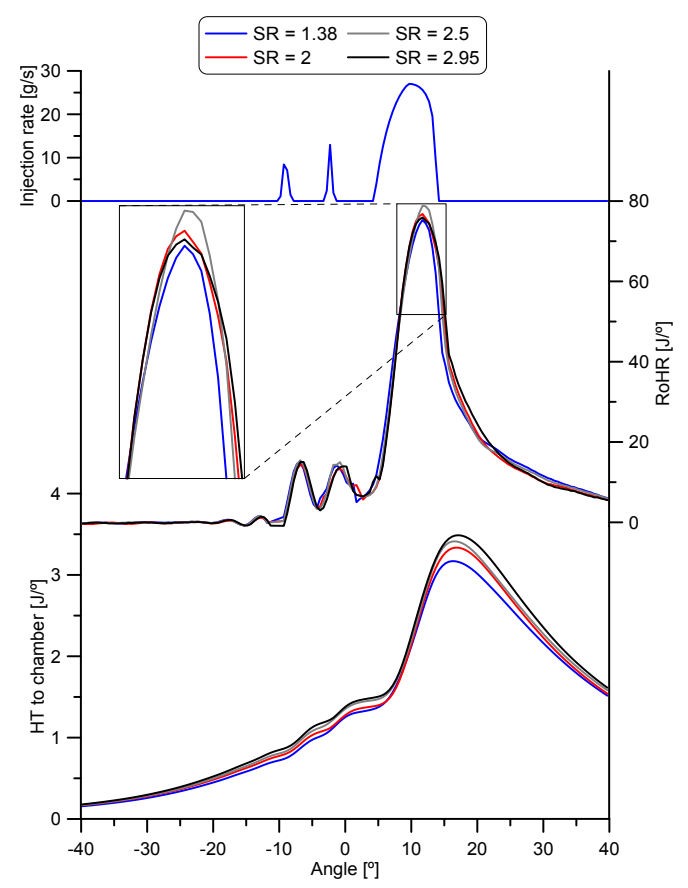

Figure 7. RoHR and HT evolution at 1500_8

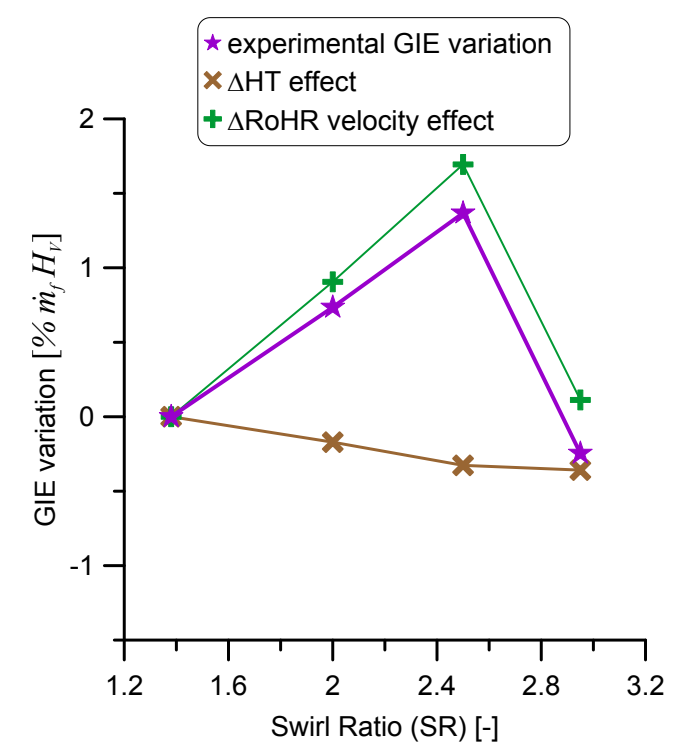

Figure 8. Split of losses study at 1500_8

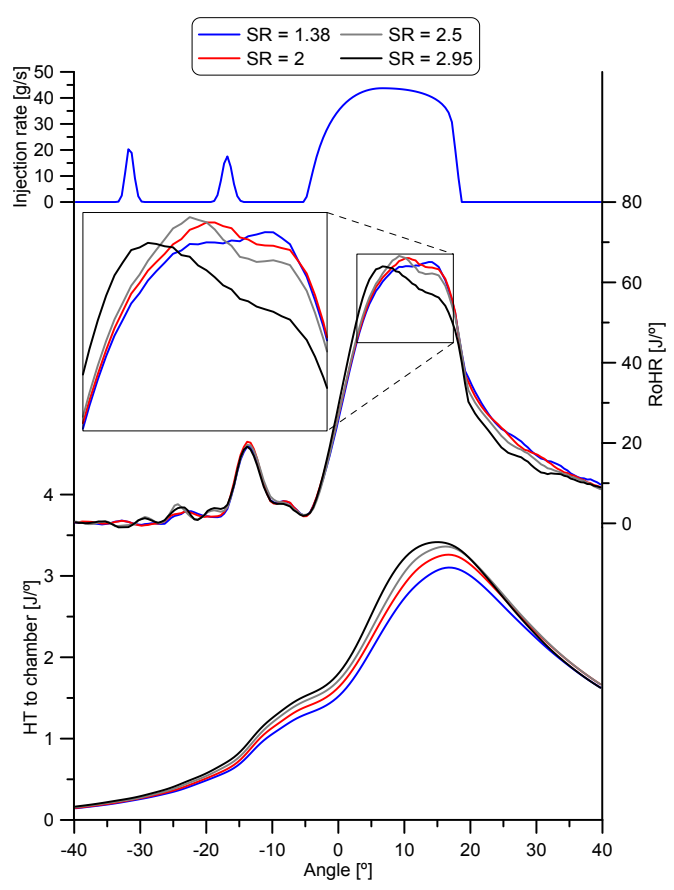

Figure 9. RoHR and HT evolution at 3000_14

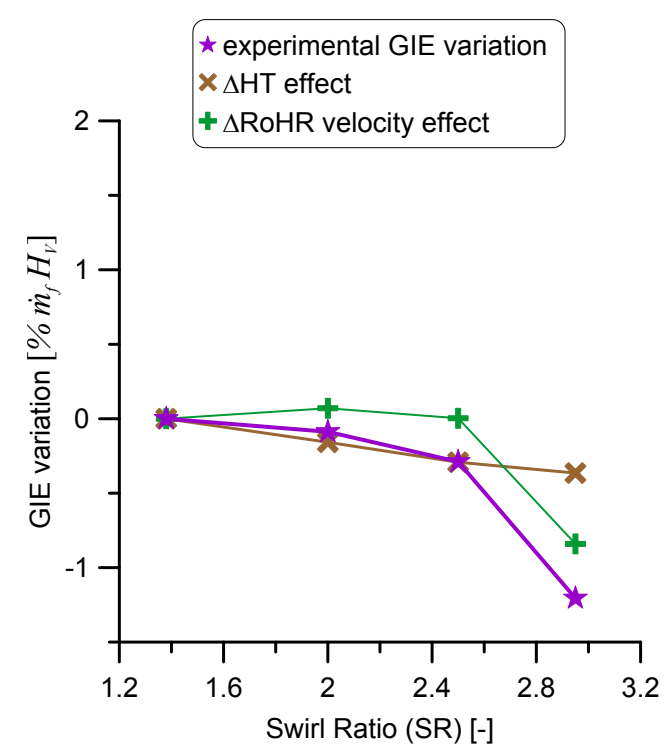

Figure 10. Split of losses study at 3000_14 


\section{Tables}

Table 1. Engine technical data

Table 2. Test cell instrumentation

Table 3. Measured operational k-points in SR sweep 


\begin{tabular}{ll}
\hline Cylinder & 4 in-line \\
Stroke & $90.4 \mathrm{~mm}$ \\
Bore & $82 \mathrm{~mm}$ \\
Geometric CR & $17.5: 1$ \\
Number of valves/cylinder & 4 \\
Air Management & Turbocharged \\
Maximum power & $110 \mathrm{~kW} @ 4000 \mathrm{rpm}$ \\
Maximum torque & $315 \mathrm{Nm} @ 2000 \mathrm{rpm}$ \\
Cycle & Diesel \\
Injection & Common rail \\
Swirl ratio variation & $1.4-3$ \\
\hline
\end{tabular}

Table 1. Engine technical data

\begin{tabular}{ll} 
Variable & Equipment \\
\hline Cylinder pressure & Kistler 6125C \\
Speed & Dynamometer \\
Torque & Dynamometer \\
Air mass flow & AVL Flowsonix Air \\
Fuel mass flow & AVL 7333S Fuel meter \\
Control fluids temperature & K-type thermocouples \\
GEB fluids temperatures & PT100 Thermoresistances \\
Material walls temperature & K-type thermocouples \\
Mean pressure & Kistler Piezoresistive Pressure Transmitters \\
Gases analysis & Horiba Mexa 7100 DEGR \\
Coolant flow rate & Krohne 4010 Optiflux \\
Oil cooler water flow rate & Yoko Admag AE2018MG Isoil M8500 \\
\hline
\end{tabular}

Table 2. Test cell instrumentation 


\begin{tabular}{lc|ccccccc}
$\begin{array}{l}\text { Speed } \\
\text { [rpm] }\end{array}$ & $\begin{array}{c}\text { BMEP } \\
{[\mathrm{bar}]}\end{array}$ & $\begin{array}{c}\text { SR } \\
{[-]}\end{array}$ & $\begin{array}{c}\text { Boost pressure } \\
{[\mathrm{bar}]}\end{array}$ & $\begin{array}{c}\text { Air mass flow } \\
{[\mathrm{g} / \mathrm{s}]}\end{array}$ & $\begin{array}{c}\text { EGR } \\
{[\%]}\end{array}$ & $\begin{array}{c}\text { Rail pressure } \\
{[\mathrm{b} \text { [br] }}\end{array}$ & $\begin{array}{c}\text { SOE Main } \\
{[\mathrm{deg} \text { ATDC] }}\end{array}$ & $\begin{array}{c}\text { Total fuel quantity } \\
{[\mathrm{mg} / \mathrm{cc}]}\end{array}$ \\
\hline $\mathbf{1 5 0 0}$ & $\mathbf{8}$ & $\mathbf{1 . 4 / 3}$ & $\mathbf{1 . 3 3} / \mathbf{1 . 3 8}$ & $\mathbf{2 9 . 8}$ & $\mathbf{0}$ & $\mathbf{7 5 0}$ & $\mathbf{0 . 8} / \mathbf{1 . 4}$ & $\mathbf{2 6 . 5}$ \\
$\mathbf{1 5 0 0}$ & $\mathbf{1 4}$ & $\mathbf{1 . 4} / \mathbf{3}$ & $\mathbf{1 . 7 3} / \mathbf{1 . 7 8}$ & $\mathbf{3 8 . 5}$ & $\mathbf{0}$ & $\mathbf{1 0 5 0}$ & $\mathbf{0 . 1 5} / \mathbf{0 . 1}$ & $\mathbf{4 5 . 8}$ \\
2000 & 2 & $1.4 / 3$ & $1.17 / 1.23$ & 38.8 & 0 & 450 & $0.2 / 0.7$ & 9.8 \\
2000 & 5 & $1.4 / 3$ & $1.36 / 1.44$ & 44.0 & 0 & 650 & $-1.2 /-0.4$ & 17.7 \\
2000 & 14 & $1.4 / 3$ & $2.29 / 2.46$ & 72.3 & 0 & 1250 & $-3.5 /-3.7$ & 50.4 \\
$\mathbf{3 0 0 0}$ & $\mathbf{1 4}$ & $\mathbf{1 . 4} / \mathbf{3}$ & $\mathbf{1 . 9 3} / \mathbf{2 . 1 6}$ & $\mathbf{8 8 . 5}$ & $\mathbf{0}$ & $\mathbf{1 4 0 0}$ & $\mathbf{- 1 1 . 1 / - 1 1}$ & $\mathbf{4 3 . 4}$ \\
\hline
\end{tabular}

Table 3. Measured operational k-points in SR sweep 


\section{Appendix}

Heat transfer to the chamber is calculated with a modified Woschni-like model [34], where the convective heat transfer coefficient is obtained using Equation 1:

$h=C D^{-0.2} p^{0.8} T^{-0.53}\left[C_{W 1} c_{m}+C_{W 2} c_{u}+C_{2} \frac{V_{d} T_{I V C}}{V_{I V C} p_{I V C}}\left(p-p_{0}\right)\right]^{0.8}$

(1)

where $C$ is a constant whose value is $0.12, D$ is the cylinder diameter, $p$ and $T$ are the in-cylinder instantaneous pressure and gas mean temperature respectively, $c_{m}$ is the mean piston speed, $c_{u}$ is the instantaneous tangential velocity of the gas in the chamber (see [34] for a detailed description of this term), $p_{0}$ is the pressure in motoring conditions assuming a polytropic evolution, $C_{W 1}, C_{W 2}$ and $C_{2}$ are constants to be adjusted; $V_{D}$ is the displaced volume and $T_{I V C}, V_{I V C}$ and $p_{I V C}$ are the temperature, volume and pressure respectively at the intake valve closing. 